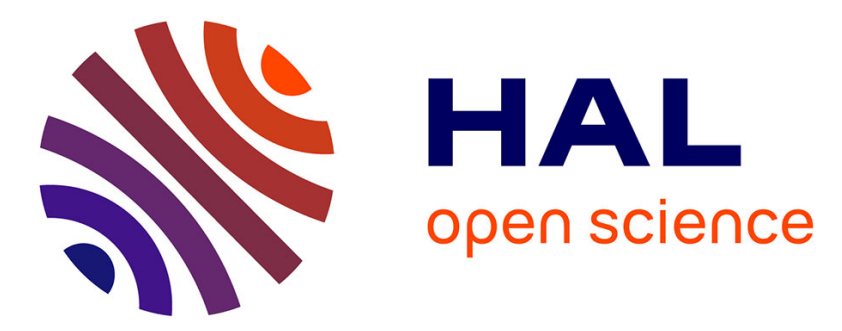

\title{
Using temporary emigration to inform movement behaviour of cave-dwelling invertebrates: a case study of a cave harvestman species
}

Raluca I Băncilă, Roger Pradel, Rémi Choquet, Rodica Plăiaşu, Olivier

Gimenez

\section{To cite this version:}

Raluca I Băncilă, Roger Pradel, Rémi Choquet, Rodica Plăiaşu, Olivier Gimenez. Using temporary emigration to inform movement behaviour of cave-dwelling invertebrates: a case study of a cave harvestman species. Ecological Entomology, 2018, 43 (5), pp.551 - 559. 10.1111/een.12645 . hal03499394

\section{HAL Id: hal-03499394 \\ https://hal.science/hal-03499394}

Submitted on 4 Jan 2022

HAL is a multi-disciplinary open access archive for the deposit and dissemination of scientific research documents, whether they are published or not. The documents may come from teaching and research institutions in France or abroad, or from public or private research centers.
L'archive ouverte pluridisciplinaire HAL, est destinée au dépôt et à la diffusion de documents scientifiques de niveau recherche, publiés ou non, émanant des établissements d'enseignement et de recherche français ou étrangers, des laboratoires publics ou privés. 

a case study of a cave harvestman species

6 1،Emil Racoviţă” Institute of Speleology of Romanian Academy, 13 Septembrie Road, No. 13, 050711,

7 Bucharest, Romania

$8{ }^{2}$ University Ovidius Constanţa, Faculty of Natural Sciences, Al. Universităţii, corp B, Constanţa, 9 Romania

$10{ }^{3}$ CEFE UMR 5175, CNRS - Université de Montpellier - Université Paul-Valéry Montpellier - EPHE,

111919 Route de Mende, 34293 Montpellier Cedex 5, France

12

13 Corresponding author: Raluca I. Băncilă

14 “Emil Racoviţă" Institute of Speleology of Romanian Academy

1513 Septembrie Road, No. 13

16 050711, Bucharest

17 Romania

18 e-mail: raluca.bancila@ieu.uzh.ch 
Abstract

Cave systems are less transparent than surface habitats and significantly less is known about

30 movement patterns and intrinsic behavioural processes of cave-dwelling animals. Here, we introduce

31 temporary emigration (TE), the probability that an individual is absent from a cave at a given sampling

32 occasion, to inform about movement and behavior of cave-dwelling animals. Because these animals are

33 difficult to study with traditional tracking techniques, we resort to the capture-recapture (CR) modeling

34 framework to assess TE to account for detectability less than one and unobservable states. We

35 investigated the influence of cave, surface weather variables, season, individual heterogeneity and sex on

36 the TE of the subtroglophile harvestman species, Paranemastoma silli. We used multistate CR models on

37999 individually marked adults of two P. silli populations inhabiting two caves, Closani and Lazului

38 Caves, located in the Mehedinti Mountains in southwestern Romania. Adult harvestmen demonstrated

39 clear seasonality and heterogeneity in TE. We found that TE of harvestmen exhibited between caves

40 variation and there was little support for surface weather variables in controlling TE and for sex specific

41 TE patterns. Our results highlight that the study of TE patterns is useful to gain valuable insights into

42 movement and intrinsic behavioural processes of cave-dwelling species.

Key words: animal movement and behavior, cave-dwelling species, individual heterogeneity,

45 season, temporal emigration

46

47

48

49

50 


\section{Introduction}

Understanding animal movements is important in animal ecology because of the profound

57 implications for population dynamics (Piper 2011). Animal movements are inextricably bound to

58 behavioural processes (Miriam et al. 2013), e.g. animals move to feed, find mates and avoid predators or

59 unfavorable environmental conditions. Hence understanding why and how animals move is not complete

60 without an understanding of the animal behaviour. Furthermore, several studies have documented

61 individual variation (individuality) in movement patterns (Vardanis et al. 2011; Brodersen et al. 2012).

62 The recognition of individuality can provide fresh insights in the causes and consequences of individual

63 differences in movement that behavioural ecology has already taken.

64 The literature exploring animal movement and behaviour is primarily focused on terrestrial and

65 oceanic systems. Cave systems are much less transparent and significantly less is known about movement

66 of cave-dwelling animals. Understanding where and how cave species travel through space is particularly

67 important. This will allow us to gain valuable insights into broader ecological effects and consequences of

68 general processes such as subsurface dispersal or migration (Culver and Pipan 2009) or behavioural

69 processes such as foraging and breeding movements (Woiwod et al. 2000).

70 However, cave-dwellers, especially invertebrates, are difficult to study. The most commonly used

71 techniques (e.g. radio transmitters or satellite technology) to track animal movement patterns and

72 behavioural processes (Rubenstein and Hobson 2004) are of no use in caves. Individual tags provided

73 good data for larger animals but not for many smaller ones. Advances in the use of stable isotope markers

74 offer new promise for insects (Hobson 2005) but the cost are still prohibitive.

75 Multistate capture-recapture (CR) methods allow estimation of temporary emigration (TE)

76 (Pradel 2005). TE is the transition from an "observable" state to an "unobservable" state, and back to an

77 “observable" state (Chapple el al. 2016). TE is widely recognized in animals and plants and was attributed

78 to a physiological condition, reproductive status, behavioural state or location (Schaub et al. 2004). Here, 
79 we argue that an important application of TE, especially for cave-dwellers, is to inform about animal

80 movements over space, e.g. emigration from and immigration to cave. Frequently sampling is conducted

81 only in cave. Considering a multistate CR model with states "observable" and "unobservable" between

82 which individuals are allowed to move, the transition from an "observable" to an "unobservable" state is

83 the emigration, the probability that an individual has moved out (emigrated) from cave between capture

84 occasion $i$ and $i+1$ while the transition back to an "observable" state is the immigration, the probability

85 that an individual has returned (immigrated) to cave during capture occasion. Mutistate CR methods have

86 been also developed to model individual heterogeneity in capture and demographic rates (Pledger et al.

87 2003; Pradel 2009; Gimenez and Choquet 2010) and there is increased evidence that unmodeled

88 individual heterogeneity causes bias in capture and survival estimates (Pledger and Efford 1998; Fletcher

89 et al. 2012). While individual heterogeneity is expected in movement patterns, no CR study investigated

90 the effect of individual heterogeneity on TE.

91 Subtroglophiles are a category of non-obligate cave-dwellers defined as species intimately

92 associated to cave environments, but requiring the epigean habitats during some period, or to complete

93 some biological function such as reproduction or feeding (Lunghi et al. 2013). Those species likely have

94 strong seasonality in the emigration/immigration rates. One can hypostatize high emigration and low

95 immigration in spring, summer and fall and low emigration and high immigration in winter. Due to

96 reliance on surface habitat of the subtroglophiles the emigration/immigration rates may depend also on

97 cave microclimate or surface environmental factors, e.g. surface weather variables. Moreover, it is

98 commonly assumed that intra-specific competition avoidance plays an important role in promoting

99 emigration (Dieckmann et al. 1999). In caves the food resources are very scarce and cave-dwellers might

100 experience strong inter- and intra-specific competition. The variation in competitive abilities may

101 generate individual heterogeneity in emigration/immigration rates. Individuals that decide to remain

102 inside cave are expected to be more competitive and fight for these scarce resources while individuals that

103 decide to leave and feed outside cave are expected to be less competitive. 
In this study we investigated the influence of cave, surface weather variables, season, individual

105 heterogeneity and sex on the TE of the subtroglophile harvestman species, Paranemastoma silli. We used

106 a multistate CR model on 999 individually marked adults of two P. silli populations inhabiting two caves,

107 Closani and Lazului Caves, located in the Mehedinti Mountains in southwestern Romania. To quantify

108 individual heterogeneity, we used two discrete classes of individuals that refer to two possible paths:

109 competitive individuals and uncompetitive individuals. We predict that season and individual

110 heterogeneity have significant effect on TE. We expect that less competitive individuals to show high

111 seasonal TE while more competitive individuals will experience lower TE regardless of season. We

112 predict that TE is different between the two caves because the caves are characterized by different

113 microclimates. We expect that surface weather variables have an effect on TE because weather is known

114 to affect the demography of organisms. We predict sex-specific patterns in TE because of possible

115 disparate demography or behaviour between the sexes.

$116 \quad$ Material and methods

$117 \quad$ Study area and capture details

118 Paranemastoma silli (Hermann 1871; Dyspnoi: Nemastomatidae) is an subtroglophilic endemic

119 harvestman species in the Carpathian Mountains (Avram \& Dumitrescu 1969) that inhabits caves but also

120 habitats outside caves, especially beech forests.

121 We conducted a CR study of P. silli in two caves: Closani and Lazului. The caves are located in

122 Mehedinti Mountains, southwestern Romania, at 433 and 370 m a.s.l., respectively. The caves are ca. 3

$123 \mathrm{~km}$ apart.

124 The caves differ in the hydrological regime, surface vegetation and food resources. Closani Cave

125 is a hydrologically inactive cave and the outside habitat consists mainly of dry scrubs. Lazului Cave is a

126 hydrologically active cave and is located in a beech forest. Closani Cave has an old guano deposits

127 whereas in Lazului Cave little amounts of fresh guano are present.

128 We conducted visual encounter surveys to search for harvestmen in teams of two researchers 129 once a month between December 2008 and November 2009, separately in each cave. We individually 
marked all caught adult harvestmen using non-toxic acrylic ink (Mestre amd Pinto-da-Rocha 2004). A

131 combination of different colour marks that were still recognizable after several recaptures was used to

132 individually mark each harvestman. The marked individuals were released at the place where they were

133 collected. The immature stages were not marked because they moult six times in $\sim 2.5$ months (Avram

134 1973). The adult harvestmen were sexed based on the cheliceral morphology.

135 The daily temperature and rainfall values were recorded at Closani village, with an iROX PRO-X

136 portable weather station. Temperature and rainfall were included in the study as mean air surface

137 temperature and mean precipitation amount during the day of capture occasion and during the week prior

138 to the capture occasion (tempm, precipm, tempw and precipw, respectively). All environmental covariates

139 were standardized for the analysis.

$140 \quad$ Data analysis

141 We analysed the CR data of 999 adult harvestmen for a period of 11 months using multistate CR

142 models (Lebreton et al. 2009) expressed as multievent models (Pradel 2005). We recorded the 'events' as

143 "seen" and "not seen" and considered the states "alive and observable" (OU) and "alive and

144 unobservable" (UO) and "dead" (D). Individuals that are in the state "unobservable" and dead during a

145 sampling occasion are unavailable for recapture, therefore the corresponding recapture probability is fixed 146 to 0.

147 To include individual heterogeneity in TE, we built two discrete classes of individuals, $g_{1}$ and $\mathrm{g}_{2}$,

148 which refer to two possible paths at first observation. The classes are states of the multievent model:

149 "alive and observable in $\mathrm{g}_{1}$ ", "alive and unobservable in $\mathrm{g}_{1}$ ", "alive and observable in $\mathrm{g}_{2}$ ", "alive and 150 unobservable in $\mathrm{g}_{2}$ ". The classes are associated with distinct values of the initial states.

151 For model formulation we considered: i) PП, the vector of probabilities of presence in the various 152 initial states $(\pi)$, ii) $\mathrm{P} \Phi$, the matrix of survival probabilities $(S)$; iii) $\mathrm{P} \psi$, the matrix of transition 153 probabilities $(\psi)$, corresponding to TE ; and iv) PB, the matrix of detection probabilities $(p)$. The full 154 description of the vectors and matrixes can be found in the Appendix S1. 
Because the transition probabilities depend only on the states in which an individual was before a transition we modeled TE as a Markovian or state-dependent transition (Schaub et al. 2004).

\section{Model selection}

We were interested in TE, but different model structures can be used to model the sampling

159 process and the survival on which the TE is conditional. For, example one may hypothesize that the

160 recapture differs among observers due to different levels of experience. Both capture and survival

161 probabilities may vary with time, (e.g. occasion, season) or time specific covariate (e.g., weather) or

162 harvestmen can exhibit cave and sex-specific capture and survival probabilities. Consequently, we

163 considered models representing different combinations of observer, time, cave, sex, season, tempm and

164 precipm on capture probability and cave, sex, season, tempw and precipw on survival probability. To

165 assess the hypotheses of TE we built models representing combinations of same covariates as for survival 166 probability but we distinguished between models with and without individual heterogeneity by 167 considering no classes or two classes, respectively, in matrix of transition probabilities, associated with 168 distinct values of the initial states (for details see Appendix S1).

In total we designed 119 models. We used E-SURGE 1.9.0 (Choquet et al. 2009a) to perform

170 model selection based on Akaike's Information Criterion corrected for small sample size (QAICc)

171 (Burnham and Anderson 1998) and to obtain maximum likelihood estimates of the parameters. In the 172 results, for brevity we choose to present only the models with $\Delta \mathrm{AICc}<20$.

175 chance of recapture of first encountered individuals than individuals already encountered (Pradel et al.

176 1997) and Test2.CT for trap-dependence and for trap-happiness (higher probability to encounter at time

$177 t+1$ the individuals encountered at time $t$ than to individuals not encountered at time $t$ but known to be 178 alive because of previous and future recaptures). We computed the overall and separately on cave and sex 179 GOF-statistics for transience and trap-dependence, from Test 3 and Test 2 respectively. The GOF tests 180 were performed using U-CARE (Choquet et al. 2009b). 


\section{Results}

The directional tests for transience and trap-happiness were statistically not significant, thus there

183 was no need to correct for transience or trap-happiness or to account for overdispersion (Table 1).

From the set of the candidate models, the model with heterogeneity and season effect on TE,

185 along with cave and sex on survival and cave, sex and tempm on recapture was best supported by the data

186 (Table 2). The model with no heterogeneity, season and cave effect on TE, along with cave and sex on

187 survival and time on recapture received some support and was the second-ranked at $3.860 \Delta \mathrm{AICc}$ after the 188 best model (Table 2).

We estimated parameters from the best model (Fig 1-3). Recapture decreased with the increase of

190 the temperature during the day of capture occasion in both caves and sexes (Fig.1). Recapture was the

191 higher in males from Closani than from Lazului cave and lower in females from Closani than from 192 Lazului cave (Fig.1). The emigration probability was high in autumn, spring and summer for $\mathrm{g}_{1}$ 193 individuals and low for $\mathrm{g}_{2}$ in all seasons except winter (Fig. 2). The immigration was high in autumn for $194 \mathrm{~g}_{1}$ individuals and high in spring and summer for $\mathrm{g}_{2}$ individuals (Fig. 3).

\section{Discussion}

In this study the application of a multistate CR model was able to estimate relevant demographic

197 parameters to inform movement patterns and behavioural processes, when data cannot be collected for 198 other established frameworks, e.g. animal tracking techniques. Our approach revealed clear seasonality 199 and captured individual heterogeneity in the TE of a subtroglophile harvestman species.

200 Seasonal variation in TE is likely due to foraging behavior. Foraging movements from cave were 201 reported for many bat (Kunz 1982) and several cricket species (Fagan et al. 2007). Strong seasonality is 202 also in agreement with studies on activity rhythm of non-obligate cave harvestmen species. Several 203 studies showed that harvestmen use caves as shelters and reproductive sites but leave the cave 204 periodically to forage (Hoenen and Gnaspini 1999; Machado et al. 2003).

205 Using assumptions of two heterogeneity classes during model construction, we showed 206 significant different patterns of emigration/immigration among seasons between the two classes. 
207 Although we can only speculate on this the heterogeneity in TE is likely linked to differences in the 208 competitive abilities for food. The scarcity of the food resources in caves is common and it has been 209 shown that non-obligate cave-dwellers forage primarily external rather than within cave (Kunz 1982; 210 Fagan et al. 2007). However, some individuals reside inside the cave and rely upon the resources 211 available in cave, maybe due to their better competitive abilities. This question requires experimental 212 studies to test whether individuals showing good competitive abilities are more likely to reside in cave 213 and if these inter-individual differences are consistent across time.

214 The results further indicated that once the heterogeneity is not accounted for, season and cave 215 drive the observed emigration/immigration rates. The two studied caves have different microclimate 216 (Decu et al. 1967). They are characterized by different hydrological regime, airflow, temperature, 217 humidity, guano deposit and outside surface habitat. This indicates that TE may be promoted by 218 variability in cave microclimate.

219 We found little support for surface weather variables in controlling TE. Weather is known to 220 affect directly and indirectly the demography of organisms (Moreno and Møller 2011). The lack of an 221 effect of surface weather variables on TE suggests that caves buffer well the fluctuations of weather 222 factors in the habitats above and reinforce the hypothesis of caves as refuges from unfavorable surface 223 environmental conditions (e.g., too dry or too hot) (Manenti et al. 2009, 2011, 2013; Ficetola et al. 2012). 224 Results also showed no strong support for sex differences in TE. Sexual disparity in TE was 225 linked to disparate demography or behaviour between sexes (Chapple et al. 2016). Movement is the result 226 of interactions between morphology, physiological performances (movement capacity), and behavioural 227 decisions (movement decision) (Ducatez et al., 2013). Additional studies are necessary to test TE sex228 dependency in correlation with various movement traits.

229 TE was until recently viewed as causing problems in CR studies and several approaches have 230 been developed for dealing with it (Fujiwara and Caswell 2002; Kendall and Nichols 2002). In this study 231 we presented TE (Schaub et al. 2004) as the parameter of biological interest and we provided a pertinent 232 framework within which to consider TE as transition between an observable and unobservable state. The 
233 TE approach of a multistate CR model can be applied to other studies to gain information on movements

234 pattern and behavioural processes of animals difficult to track with the available intrinsic and extrinsic

235 tracking techniques. Moreover, it can be used when a robust design (Pollock 1982), e.g. sampling

236 replication (secondary occasions) within each season (primary occasion) cannot be implemented.

237 However, it is still preferable to sample all potential locations of marked individuals and we recommend

238 muti-state CR approach where unobservable states are inevitable but in general we recommend setting up

239 a study under Pollock’s (1982) robust design.

\section{Acknowledgements}

This work was supported by a short-term postdoctoral research fellowship offered by French

242 Embassy and French Institute of Romania and a grant of Romanian National Authority for Scientific

243 Research, CNCS - UEFISCDI, projects number: PN-II-RU-TE-2014-4-1536 to RB.

$244 \quad$ References

245 Avram, Ş., Dumitrescu, D. (1969). Contributii la cunoasterea raspindirii geografice si a ecologiei 246 opilionidelor cavernicole, endogee si epigee, din Romania. Trav. Inst. Spéol. E. Racovitza, 8, 99$247 \quad 145$

248 Avram, Ş. 1973. Contribution à la connaissance du développement embryonnaire et postembryonnaire 249 chez Nemastoma cf. sillii Herman (Opiliones, Nemastomatidae). Livre Cent. Trav. Inst. Spéol. E. $250 \quad$ Racovitza, 269-303.

251 Brodersen J., Nilsson P. A., Chapman B. B., Skov C., Hansson L. -A., Brönmark C. (2012). Variable 252 individual consistency in timing and destination of winter migrating fish. Biol. Letters, 8, 21-23. $253 \quad$ DOI: $10.1098 / \mathrm{rsbl} .2011 .0634$

254 Burnham, K. P., Anderson, D.R. (2002). Model selection and multimodel inference a practical 255 information-theoretic approach. Springer, New York, USA. 
Chapple, T. K., Chambert, T., Kanive, P. E., Jorgensen, S. J., Rotella, J. J., Anderson, S. D., Carlisle A. B., Block, B. A. (2016). A novel application of multi-event modeling to estimate class segregation in a highly migratory oceanic vertebrate. Ecology. DOI: 10.1002/ecy.1589

Choquet, R., Rouan, L., Pradel, R. (2009)a. Program E-SURGE: A software application for fitting multievent models. Pages 845-865 in D. L. Thomson, E. G. Cooch, and M. J. Conroy. Environmental and Ecological Statistics, Volume 3.

Choquet, R., Lebreton, J. D., Gimenez, O., Reboulet, A. M., Pradel, R. (2009)b. U-CARE: utilities for performing goodness of fit tests and manipulating capture-recapture data. Ecography, 32, 10711074. DOI: $10.1111 /$ j.1600-0587.2009.05968.x

Culver, D. C., Pipan, T. (2009). The biology of caves and other subterranean habitats. New York: Oxford University Press.

Decu, A., Decu, V., Bleahu, M. 1967. Recherches sur les Grottes du Banat et d'Olténie. Paris: CNRS.

Dieckmann, U., O'Hara, B., Weisser, W. (1999). The evolutionary ecology of dispersal. Trends Ecol. Evol., 14, 88-90. DOI: 10.1016/S0169-5347(98)01571-7 .

Ducatez, S., Legrand, D., Chaput-Bardy, A., Stevens, V. M., Fréville, H., Baguette, M. (2012). Interindividual variation in movement: is there a mobility syndrome in the large white butterfly Pieris brassicae? Ecol. Entomol., 37, 377-385. DOI:10.1111/j.1365-2311.2012.01375.x

Fagan, W. F., Lutscher, F., Schneider, K. (2007). Population and community consequences of spatial subsidies derived from central-place foraging. Am. Nat., 170, 902-915. DOI: 10.1086/522836.

Ficetola, G. F., Pennati, R., Manenti, R. (2012). Do cave salamanders occur randomly in cavities? An analysis with Hydromantes strinatii. Amphibia-Reptilia 33, 251-259. DOI:10.1163/156853812X638536

Fletcher, D., Lebreton, J. -D., Marescot, L., Schaub, M., Gimenez, O., Dawson, S., Slooten, E. (2012). capture heterogeneity. Methods Ecol. Evol., 3, 206-216. DOI: 10.1111/j.2041-210x.2011.00137.x 
Fujiwara, M., and H. Caswell. (2002). Estimating population projection matrices from multi-stage markrecapture data. Ecology, 83, 3257-3265. DOI: 10.2307/3072076

Gimenez, O., Choquet, R. (2010). Individual heterogeneity in studies on marked animals using numerical integration: capture-recapture mixed models. Ecology, 91, 148-154. DOI: 10.1890/09-1903.1

Hobson, K. A. (2005) Flying fingerprints: making connections with stable isotopes and trace elements. In Birds of Two Worlds (Marra, P. and Greenberg, R., eds), John Hopkins University Press.

Hoenen, S., Gnaspini, P. (1999). Activity rhythms and behavioral characterization of two epigean and one cavernicolous harvestmen (Arachnida, Opiliones, Gonyleptidae). J. Arachnol., 27, 159-164.

Kendall, W. L., Nichols, J. D. (2002). Estimating state-transition probabilities for unobservable states using capture-recapture/resighting data. Ecology, 83, 3276-3284. DOI: 10.2307/3072078

Kunz, T. 1982. Ecology of Bats, New York: Plenum Press, 425 pp.

Lebreton, J. -D., Nichols, J. D., Barker, R. J., Pradel, R., Spendelow, J. A. (2009). Modeling individual animal histories with multistate capture-recapture models. In Hal Caswell, editor: Advances in Ecological Research, Vol. 41, Burlington: Academic Press, pp. 87-173. ISBN: 978-0-12-374925-

Lunghi, E., Manenti, R., Ficetola, G. F. (2014). Do cave features affect underground habitat exploitation by non-troglobite species? Acta Oecol., 55, 29-35. DOI:org/10.1016/j.actao.2013.11.003

Machado, S. F., Ferrira, R. L., Martins, R. P. (2003). Aspects of the population ecology of Goniosoma sp (Arachnida Opiliones Gonyleptidae) in limestone caves in southeastern Brazil. Tropical Zoology, $16,13-31$.

Manenti, R., Ficetola, G. F., Bianchi, B., De Bernardi, F. (2009). Habitat features and distribution of Salamandra salamandra in underground springs. Acta Herpetol., 4, 143-151. DOI:org/10.13128/Acta_Herpetol-3416

Manenti, R., Ficetola, G. F., Marieni, A., De Bernardi, F. (2011). Caves as breeding sites for Salamandra salamandra: habitat selection, larval development and conservation issues. North-West. J. Zool., 7, 304-309. 
Manenti, R., Siesa, M. E., Ficetola, F. (2013). Odonata occurence in caves: active or accidentals? A new case study. J. Cave Karst Stud., 75, 205-209. DOI: 10.4311/2012LSC0281

Mestre, L. A. M., Pinto-da-Rocha, R. (2004). Population dynamics of an isolated population of the Harvestmen Ilhaia cuspidata (Opiliones, Gonyleptidae), in Araucaria Forest (Curitiba, Paraná, Brazil). J. Arachnol., 32, 208-220.

Miriam, L., Chapman, B. B., Rachel, M., Åkesson, S. (2013). The behavioral ecology of animal movement: reflections upon potential synergies. Anim Migr., 1:39. DOI: 10.2478/ami-2013-0002

Moreno, J., Møller, A. P. (2011). Extreme climatic events in relation to global change and their impact on

Pledger, S., Efford, M. (1998). Correction of bias due to heterogeneous capture probability in capturerecapture studies of open populations. Biometrics, 54, 888-898. DOI: 10.2307/2533843

Pledger, S., Pollock, K. H., Norris, J. L. (2003). Open capture-recapture models with heterogeneity: I. Cormack-Jolly-Seber model. Biometrics, 59, 786-794.

Pollock, K. H. (1982). A capture-recapture design robust to unequal probability of capture. J. Wildl. Manage., 46, 752-757.

Pradel, R. (2009). The stakes of capture-recapture models with state uncertainty. Pages 781-795 in D. L. Thomson, E. G. Cooch, and M. J. Conroy, editors. Modeling demographic processes in marked populations. Environmental and ecological statistics series. Volume 3. Springer-Verlag, New York.

Pradel, R., Hines, J. E., Lebreton, J. -D., Nichols, J. D. (1997). Capture-recapture survival models taking account of transients. Biometrics, 53, 60-72. DOI: 10.2307/2533097

Pradel, R. (2005). Multievent: An extension of multistate capture-recapture models to uncertain states. Biometrics, 61, 442-447. 
332 Rubenstein, D. R., Hobson, K. A. (2004). From birds to butterflies: animal movement patterns and stable isotopes. Trends Ecol. Evol., 19, 256 - 263. DOI.org/10.1016/j.tree.2004.03.017

334 Schaub, M., Gimenez, O., Schmidt, B. R., Pradel, R. (2004). Estimating survival and temporary emigration in the multistate capture-recapture framework. Ecology, 85, 2107-2113.

336 Vardanis Y., Klaassen R. H. G., Strandberg R., Alerstam T. (2011). Individuality in bird migration: routes and timing. Biol. Lett., 7, 502-505. DOI: 10.1098/rsbl.2010.1180

338 Woiwod, I. P., Reynolds, D. R., Thomas, C.D. ed. 2000: Insect movement: mechanisms and 339 consequences. Wallington, Oxon, UK., CBI. 
Table 1. Goodness-of-fit tests showing no transience, trap-happiness or overdispersion.

\begin{tabular}{|c|c|c|c|c|c|c|c|c|c|c|c|}
\hline & & $\begin{array}{l}\text { Closani } \\
\text { Cave }\end{array}$ & & & & & & & & & \\
\hline \multirow{4}{*}{ Male } & & 3.SR & 3.SM & 2.CT & 2.CL & Global & 3.SR & 3.SM & 2.CT & 2.CL & Global \\
\hline & $x^{2}$ & 2.93 & 26.51 & 10.13 & 11.17 & 50.74 & 7.74 & 2.4 & 9.73 & 8.67 & 28.54 \\
\hline & d.f. & 10 & 11 & 9 & 10 & 40 & 9 & 5 & 8 & 8 & 30 \\
\hline & $\mathrm{p}$ & 0.98 & 0.001 & 0.34 & 0.32 & 0.12 & 0.56 & 0.79 & 0.31 & 0.37 & 0.54 \\
\hline \multirow[t]{3}{*}{ Female } & $\chi^{2}$ & 3.59 & 3.7 & 4.93 & 16.06 & 28.28 & 5.55 & 4.54 & 6.2 & 5.86 & 22.15 \\
\hline & d.f. & 9 & 11 & 9 & 12 & 41 & 7 & 5 & 7 & 6 & 25 \\
\hline & $\mathrm{p}$ & 0.94 & 0.98 & 0.84 & 0.19 & 0.93 & 0.59 & 0.47 & 0.52 & 0.44 & 0.63 \\
\hline \multirow[t]{3}{*}{ Pooled } & $x^{2}$ & & & & & 79.02 & & & & & 50.69 \\
\hline & d.f. & & & & & 81 & & & & & 55 \\
\hline & $\mathrm{p}$ & & & & & 0.54 & & & & & 0.64 \\
\hline
\end{tabular}


Table 2. Model selection with deviance (DEV), Akaike's Information Criterion corrected for small sample size (AICc), differences in AICc $(\triangle \mathrm{AICc})$ and number of estimable parameters $(\mathrm{K})$ for the candidate models with $\Delta \mathrm{AICc}<20$ (for brevity models with $\Delta \mathrm{AICc}>20$ are not shown). The candidate models vary in the presence $(\mathrm{h}+)$ and absence $(\mathrm{h}-)$ of heterogeneity in temporary emigration (TE) and effect of cave (a group variable with two categories: Closani Cave and Lazului Cave), sex (a group variable with two categories: female and male), time (capture occasion time effect), tempm (mean air surface temperature during the day of capture occasion), tempw (mean air surface temperature during the week prior to the capture occasion).

\begin{tabular}{|c|c|c|c|c|c|c|c|c|}
\hline Model & & Survival & TE & Recapture & $\mathrm{K}$ & DEV & QAICc & $\triangle \mathrm{AICc}$ \\
\hline 1 & $\mathrm{~h}+$ & cave+sex+cave:sex & season & cave+sex+tempm & 30 & 5.931 .324 & 5.991 .946 & 0.000 \\
\hline 2 & h- & cave+sex & cave+season & time & 23 & 5.949 .438 & 5.995 .806 & 3.860 \\
\hline 3 & $\mathrm{~h}+$ & cave+sex & cave+season & cave+sex+season & 28 & 5.942 .382 & 5.998 .924 & 6.979 \\
\hline 4 & $\mathrm{~h}+$ & cave+sex & cave+season & sex+season & 28 & 5.943 .232 & 5.999 .774 & 7.828 \\
\hline 5 & $\mathrm{~h}+$ & cave+sex & cave+sex+tempw & cave+sex+tempm & 46 & 5.907 .283 & 6.000 .735 & 8.789 \\
\hline 6 & $\mathrm{~h}+$ & cave+sex & season & cave+season & 26 & 5.947 .876 & 6.000 .344 & 8.398 \\
\hline 7 & $\mathrm{~h}+$ & cave+sex & sex+season & cave+sex+tempm & 38 & 5.924 .895 & 6.001 .888 & 9.942 \\
\hline 8 & h- & cave+sex+season & cave+sex & cave+sex+tempw+precipw & 28 & 5945.477 & 6002.020 & 10.074 \\
\hline 9 & $\mathrm{~h}-$ & cave+sex+season & cave+sex & cave+season & 20 & 5966.626 & 6006.905 & 14.959 \\
\hline 10 & h- & cave+sex+season & cave+sex & cave+sex+season & 24 & 5959.481 & 6007.881 & 15.935 \\
\hline
\end{tabular}




\section{Figure captions}

Figure 1. Effect of mean air surface temperature during the day of capture occasion (tempm) on monthly recapture probabilities (SE) of female and male harvestmen in Closani and Lazului Caves. Estimates are based on the most parsimonious CR model (Model 1 in Table 2).

Figure 2. Estimated seasonal emigration rates (SE) of harvestmen form the two heterogeneity classes, $g_{1}$ (grey) and $\mathrm{g}_{2}$ (black). Estimates are based on the most parsimonious CR model (Model 1 in Table 2).

Figure 3. Estimated seasonal immigration rates (SE) of harvestmen form the two heterogeneity classes, (grey) and $\mathrm{g}_{2}$ (black). Estimates are based on the most parsimonious CR model (Model 1 in Table 2). 


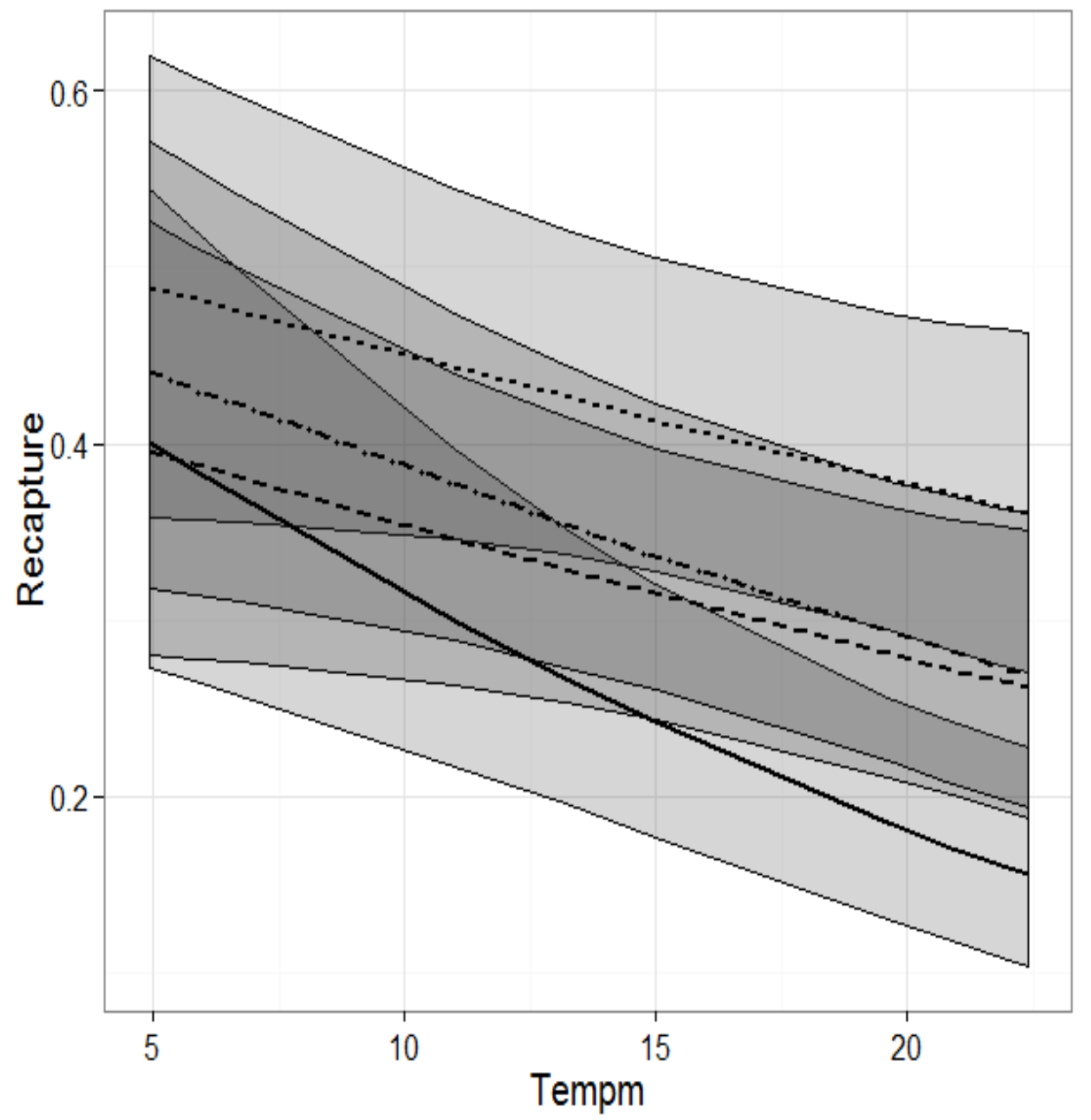

$\square$ Closani Female $\cdots$ Closani Male -- Lazului Female - Lazului Male 


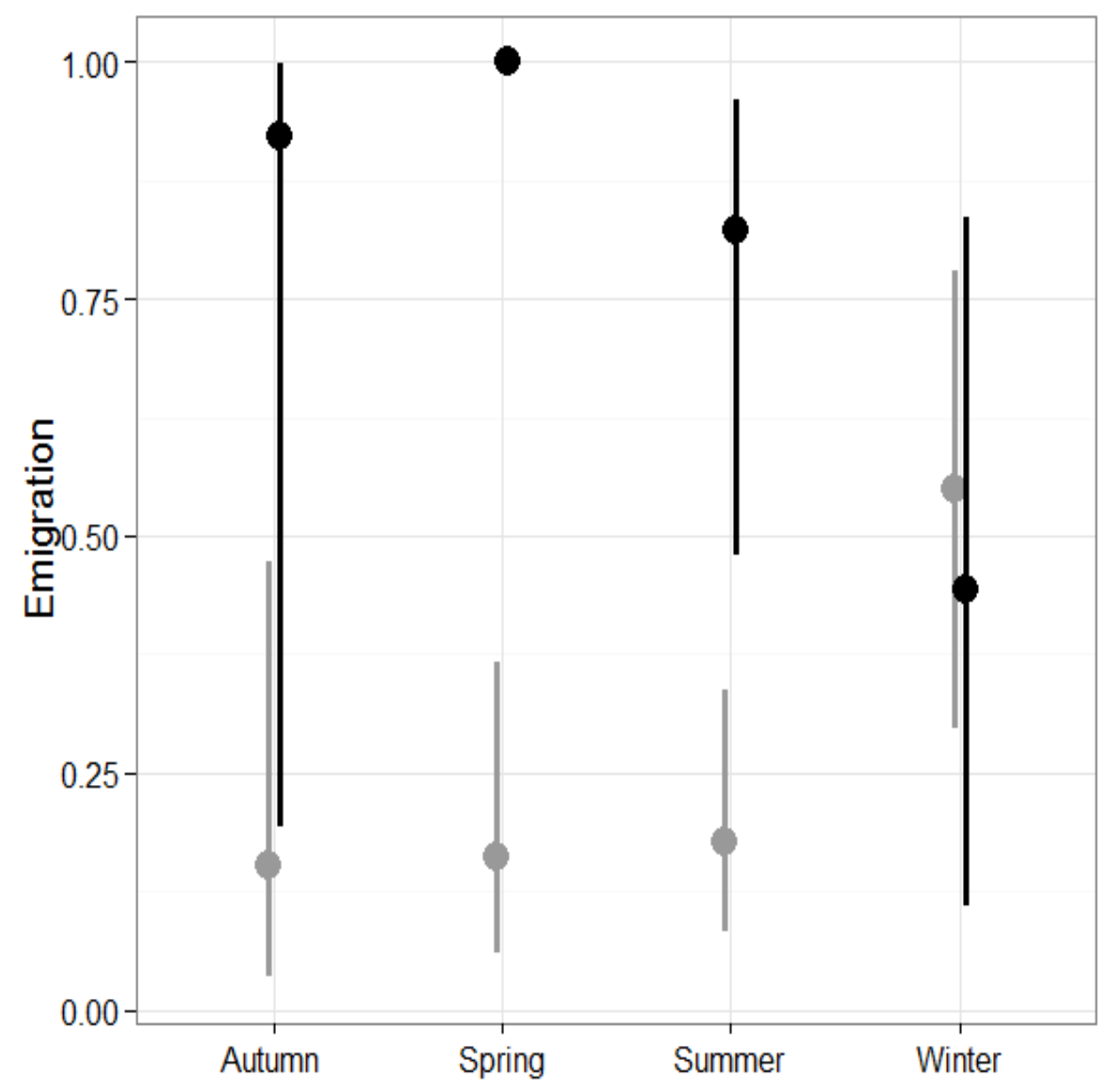




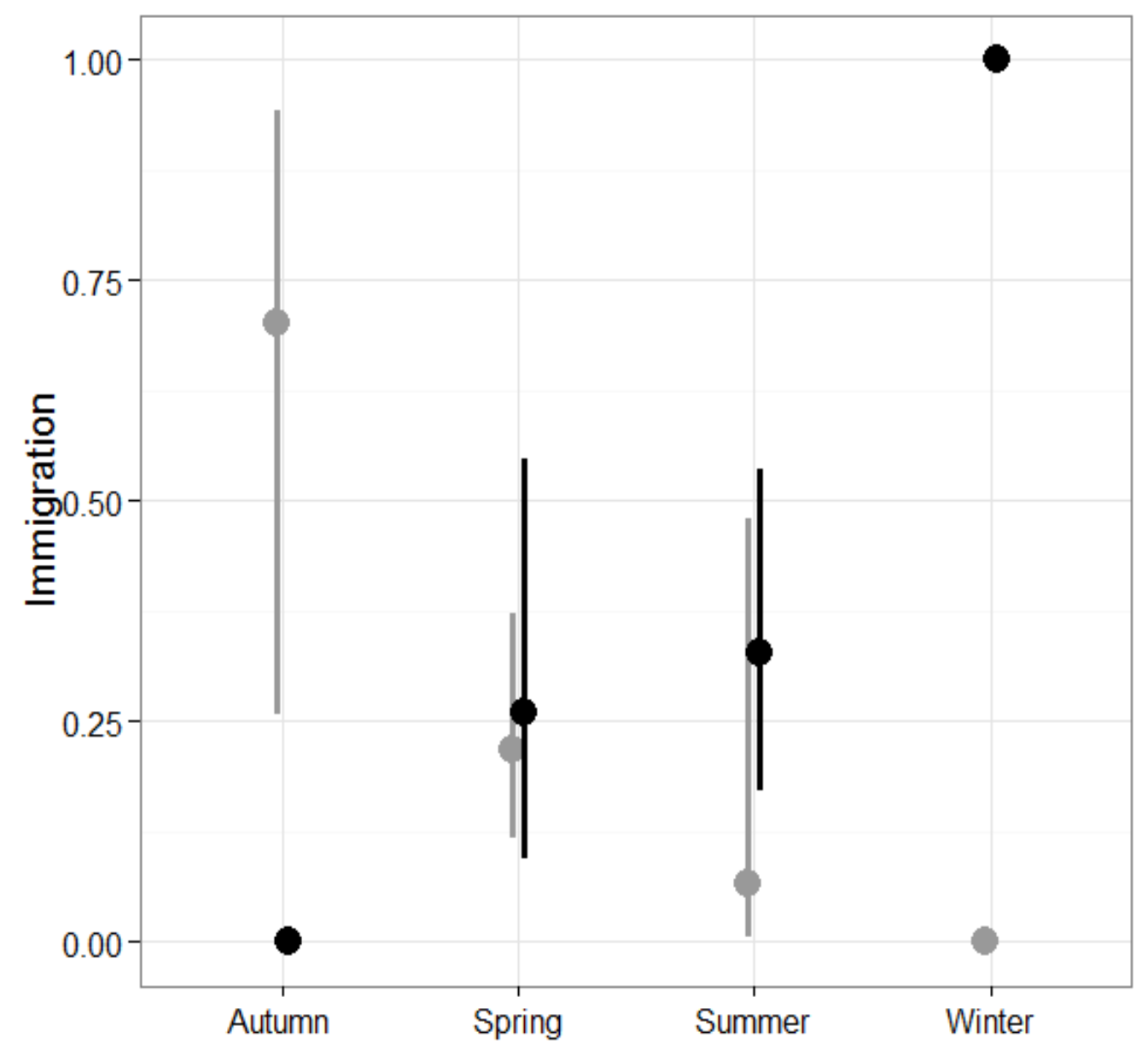

